\title{
Antithrombotic effect of epigallocatechin gallate on the patency of arterial microvascular anastomoses
}

\author{
Murat İğde ${ }^{1}$, Mehmet Onur Öztürk², Burak Yaşar ${ }^{1}$, Mehmet Hakan Bulam³ ${ }^{3}$, Hasan Murat Ergani ${ }^{1}$, \\ Ramazan Erkin Ünlü ${ }^{1}$ \\ ${ }^{1}$ Department of Plastic, Aesthetic, and Reconstructive Surgery, Ankara Numune Training and Research Hospital, Ankara; ${ }^{2}$ Department of \\ Plastic, Aesthetic, and Reconstructive Surgery, İzmir Çiğli Training and Research Hospital, İzmir; ${ }^{3}$ Department of Plastic, Aesthetic, and \\ Reconstructive Surgery, Ankara Keçiören Training and Research Hospital, Ankara, Turkey
}

Background Microvascular anastomosis patency is adversely affected by local and systemic factors. Impaired intimal recovery and endothelial mechanisms promoting thrombus formation at the anastomotic site are common etiological factors of reduced anastomosis patency. Epigallocatechin gallate (EGCG) is a catechin derivative belonging to the flavonoid subgroup and is present in green tea (Camellia sinensis). This study investigated the effects of EGCG on the structure of vessel tips used in microvascular anastomoses and evaluated its effects on thrombus formation at an anastomotic site.

Methods Thirty-six adult male Wistar albino rats were used in the study. The right femoral artery was cut and reanastomosed. The rats were divided into two groups (18 per group) and were systemically administered either EGCG or saline. Each group were then subdivided into three groups, each with six rats. Axial histological sections were taken from segments $1 \mathrm{~cm}$ proximal and $1 \mathrm{~cm}$ distal to the microvascular anastomosis site on days 5, 10, and 14 .

Results Thrombus formation was significantly different between the EGCG and control groups on day $5(P=0.015)$ but not on days 10 or 14 . The mean luminal diameter was significantly greater in the EGCG group on days $5(P=0.002), 10(P=0.026)$, and $14(P=0.002)$. Intimal thickening was significantly higher on days $5(P=0.041)$ and $10(P=0.02)$.

Conclusions EGCG showed vasodilatory effects and led to reduced early thrombus formation after microvascular repair. Similar studies on venous anastomoses and random or axial pedunculated skin flaps would also contribute valuable findings relevant to this topic.

Keywords Microsurgery / Thrombosis / Catechin / Oxidants / Vasodilatation
Correspondence: Burak Yaşar Department of Plastic, Aesthetic, and Reconstructive Surgery, Ankara Numune Training and Research Hospital, Ülkü Avenue Talatpaşa Boulevard No. 5 Altındağ, Ankara 06100, Turkey

Tel: +90-312-508-45-44 Fax: +90-312-311-43-40 E-mail: burakys@outlook.com.tr

This study was funded by the Ankara Numune Training and Research Hospital Committee for Funding Scientific Studies (grant no: 2013/457).

Received: 19 Feb 2018 - Revised: 2 Feb $2019 \bullet$ Accepted: 9 Mar 2019

pISSN: 2234-6163 • elSSN: 2234-6171 • https://doi.org/10.5999/aps.2018.00157• Arch Plast Surg 2019;46:214-220

\section{INTRODUCTION}

The patency of microvascular anastomoses is adversely affected by local and systemic factors [1]. Impaired intimal recovery and endothelial mechanisms promoting thrombus formation at the anastomotic site are common causes of decreased anastomosis 
patency [1-4]. Dextran, heparin, low-molecular-weight heparin, and steroids are commonly administered in clinical practice to prevent thrombus formation. Several drugs, including vinblastine, sildenafil, and botulinum toxin, have been used to increase anastomosis patency in experimental studies; however, the clinical applications of these drugs are currently limited $[1,2,5,6]$.

Epigallocatechin gallate, found in green tea (Camellia sinensis), is a catechin derivative belonging to the flavonoid subgroup that has been shown to exert cardioprotective, anti-atherosclerotic, anti-oxidant, vasorelaxant, anti-aggregant, and anti-inflammatory effects [7-11]. It was also shown to prevent vascular smooth muscle hypertrophy and intimal hyperplasia, to accelerate pseudointima and intima formation, to stimulate endothelial nitric oxide production, to inhibit plasminogen activator inhibitor-1 production, and to prevent thrombocyte aggregation [12]. The purpose of the present study was to investigate the effects of epigallocatechin gallate on the structure of vessel tips used in microvascular anastomoses and to determine its effects on thrombus formation at the anastomotic site.

\section{METHODS}

This study was approved by the Ankara University Medical Faculty Laboratory Animals Ethics Committee (approval number: 53184147-50.04.04/3835). Thirty-six adult male Wistar albino rats weighing $300-400 \mathrm{~g}$ were included in the present study. The rats were kept individually under a 12-hour dark/12-hour light cycle. The room temperature and humidity were maintained at $22^{\circ} \mathrm{C}$ and $30 \%$, respectively. Animals were provided with food and water ad libitum. The rats were divided into two groups, each consisting of 18 animals. The groups were systemically administered either epigallocatechin gallate or saline, as described in more detail below. Each group was further divided into three subgroups, each containing six rats. Axial sections measuring $1-\mu \mathrm{m}$ thick were cut and collected from segments 1 $\mathrm{cm}$ proximal and $1 \mathrm{~cm}$ distal to the microvascular anastomoses at 5, 10, and 14 days after anastomosis. These time-points were chosen because day 5 corresponds to the time of pseudointima formation and day 14 to permanent intima formation. Day 10 was chosen in order to evaluate whether permanent intima formation was accelerated. One rat died due to the anesthesia and two rats developed wound infections during follow-up. The infected rats were excluded, and two healthy rats were included instead. Postoperative analgesia was achieved via $700 \mathrm{mg} / \mathrm{kg} \mathrm{ac}-$ etaminophen. After collecting tissue samples at the indicated time points, the rats were sacrificed by cervical dislocation under general anesthesia.

\section{Surgical technique for anastomosis}

General anesthesia was achieved by intraperitoneal administration of $50 \mathrm{mg} / \mathrm{kg}$ ketamine $\mathrm{HCl}$ (Ketalar; Eczacıbaşı, İstanbul, Turkey) and $10 \mathrm{mg} / \mathrm{kg}$ xylazine hydrochloride $(23.32 \mathrm{mg} / \mathrm{mL}$; Rompun, Bayer Korea, Seoul, Korea). Intramuscular chlortetracycline (Devamisin; Damla İlaç, İstanbul, Turkey) was administered at a dose of $10 \mathrm{mg} / \mathrm{kg}$ as prophylaxis against infection. The right inguinal region of each rat was shaved and sterilized with Betadine solution. The region of interest was accessed by an incision in the inguinal crease. The femoral artery was dissected and prepared. A complete transverse incision was then made using straight microsurgical scissors. Vessel tips were prepared and end-to-end microvascular anastomoses were performed with eight stitches using 10/0 nylon monofilament sutures (Ethilon; Ethicon, Johnson \& Johnson, Somerville, NJ, USA). All anastomoses were carried out by the same experienced researcher who was blinded to the experimental groups.

\section{Drug administration}

Rats in the experimental group were administered epigallocatechin gallate (Sigma-Aldrich Co., St. Louis, MO, USA) once before surgery and once daily after surgery at a dose of $1 \mathrm{~mL}$ of epigallocatechin gallate solution prepared as $100 \mathrm{mg} / \mathrm{kg}$ via gastric gavage. The rats in the control group were given equivalent volumes of saline via gavage. The doses and administration protocol were previously described by Meng et al. [13], Choi et al. [14], Unno and Takeo [15].

\section{Assessment of arterial patency}

On days 5, 10, and 14 after surgery, the rats were re-operated under general anesthesia as described above. The femoral artery and vein were exposed through initial incisions, and dissected free of the adjacent tissues. Vessel patency was assessed by the "milking" test. There were no physical or macroscopic signs of thrombotic complications.

\section{Histopathology}

Simultaneously with the arterial patency assessment, rats were also examined for signs of infection or abscess formation at the anastomotic site. Rats with any of these signs were excluded from the study. In rats with a visible anastomotic site, tissue samples were collected from segments $1 \mathrm{~cm}$ proximal and $1 \mathrm{~cm}$ distal to the anastomotic site. Light microscopy was performed after irrigating the samples with saline to measure luminal diameter and intimal or medial thickening. All tissues were stored in $10 \%$ neutral-buffered formalin solution, embedded in paraffin, and stained with hematoxylin and eosin. Axial $1-\mu \mathrm{m}$ tissue sections were obtained from segments $1 \mathrm{~cm}$ proximal and $1 \mathrm{~cm}$ 


\section{Table 1. Histopathological criteria}

\begin{tabular}{|llc|}
\hline Factor & \multicolumn{1}{c}{ Criterion } & Grade \\
\hline Thrombus formation (fibrin & $<1 / 3$ Of the luminal diameter & + \\
deposition on the vessel wall) & $1 / 3-2 / 3$ Of the luminal diameter & ++ \\
& $>2 / 3$ Of the luminal diameter & +++ \\
Deficiency of elastic lamina & $<1 / 3$ Of the luminal circumference & + \\
& $1 / 3-2 / 3$ Of the luminal circumference & ++ \\
& $>2 / 3$ Of the luminal circumference & +++ \\
Intimal thickening & $1-2$ Cells thick & + \\
& $2-5$ Cells thick & ++ \\
& $>5$ Cells thick & ++ \\
Medial thickening & Mild & + \\
& Moderate & ++ \\
Adventitial inflammation & Marked & ++ \\
& Few lymphocytes & + \\
& Moderate & ++ \\
Foreign body reaction around & Few lymphocytes & ++ \\
the suture & Lymphocytes and few giant cells & ++ \\
& Diffuse lymphocytes and multiple & +++ \\
& giant cells & \\
\hline
\end{tabular}

distal to the anastomotic site. They were then examined by the same pathologist/histologist under a light microscope, applying macroscopic and microscopic histopathological criteria (Table 1). Macroscopic features included an increase in vessel diameter or a change in color. Microscopic features included thrombus formation, deficiency of the elastic lamina, intimal thickening, medial thickening, adventitial inflammation, foreign body reactions, and the mean luminal diameter (in millimeters) (Table 1).

\section{Statistical analysis}

Of the histopathological variables, the mean luminal diameter was expressed numerically, while the others were expressed ordinally (Table 1). In the descriptive statistics related to the data, median, minimum, and maximum values were calculated. The Mann-Whitney $\mathrm{U}$ test was used to compare measurements between groups. P-values $<0.05$ were considered to indicate statistical significance. All analyses were performed using SPSS version 21 (IBM Corp., Armonk, NY, USA).

\section{RESULTS}

The histopathological results of all rats are presented in Table 2 . The increase in mean vascular luminal diameter was significantly higher in the epigallocatechin gallate group on day $5(\mathrm{P}=$ $0.002)$, day $10(\mathrm{P}=0.026)$, and day $14(\mathrm{P}=0.002)$. The macroscopic color change was significantly different between groups, and the vessels were redder on only day $10(\mathrm{P}=0.015)$, not on days 5 or 14 . Thrombus formation was significantly less fre-

\section{Fig. 1. Organized thrombus}

Total arterial occlusion in the control group on day 5. Some recanalization areas can be seen at the center of the thrombus. Mild medial thickening was seen $(H \& E, \times 10)$. Thrombus formation was frequent in the control group. There were no thrombus formation in the epigallocatechin gallate group on day 5 .

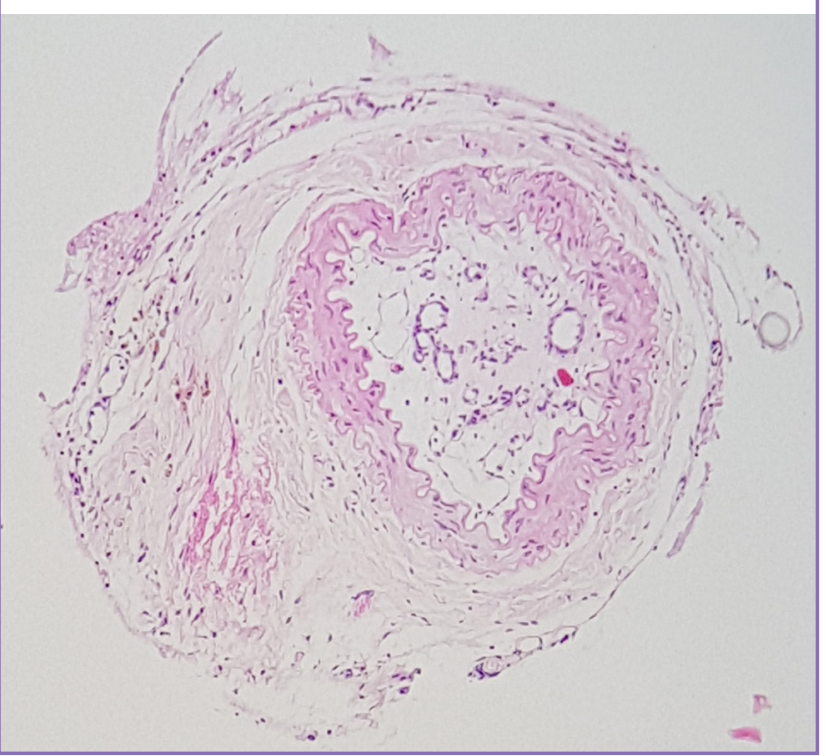

quent in the epigallocatechin gallate group on day $5(\mathrm{P}=0.015)$, but not on days 10 or 14 (Fig. 1). No significant differences were found in terms of deficiency of the elastic lamina, adventitial inflammation, and vascular foreign body reactions on days 5, 10, or 14 between the groups. Additionally, severe arterial luminal narrowing resulting from intimal thickening was seen in the control group on day 10 (Fig. 2). Medial thickening was not significantly different between groups. The most striking difference was found in the mean luminal diameter, which was significantly greater in the epigallocatechin gallate group on days 5 $(\mathrm{P}=0.002), 10(\mathrm{P}=0.026)$, and $14(\mathrm{P}=0.002)$ (Table 3$)$.

\section{DISCUSSION}

Arterial problems, especially occlusions, still pose challenges in microsurgery. Various drugs and experimental models are used to manage arterial problems in microsurgery practice.

Rats were used in this experimental study since they are commonly used to practice surgical techniques and to establish experimental models of microsurgery, such as thrombus formation after microanastomosis. The similar pharmacokinetic properties of epigallocatechin gallate in rats and humans was another reason for preferring rats in this study. All technical and environmental factors were standardized throughout the study. Because the diameter of the rat femoral artery is equivalent to the diameter of the human digital artery, which is involved in 
Table 2. Histopathological findings

\begin{tabular}{|c|c|c|c|c|c|c|c|c|c|c|}
\hline No & Group & $\begin{array}{l}\text { Diameter } \\
\text { increase }\end{array}$ & $\begin{array}{l}\text { Color } \\
\text { change }\end{array}$ & $\begin{array}{l}\text { Presence of } \\
\text { a thrombus }\end{array}$ & $\begin{array}{l}\text { Deficiency of the } \\
\text { elastic lamina }\end{array}$ & $\begin{array}{c}\text { Intimal } \\
\text { thickening }\end{array}$ & $\begin{array}{c}\text { Medial } \\
\text { thickening }\end{array}$ & $\begin{array}{l}\text { Adventitial } \\
\text { inflammation }\end{array}$ & $\begin{array}{l}\text { Foreign } \\
\text { body } \\
\text { reaction }\end{array}$ & $\begin{array}{c}\text { Mean luminal } \\
\text { diameter } \\
(\mathrm{mm})\end{array}$ \\
\hline 1 & C5 & - & - & - & - & - & - & + & + & 0.3 \\
\hline 2 & C5 & - & - & +++ & - & - & - & + & + & 0 \\
\hline 3 & C5 & - & - & +++ & + & + & - & - & + & 0 \\
\hline 4 & C5 & - & + & +++ & + & - & - & + & ++ & 0 \\
\hline 5 & C5 & - & - & +++ & - & - & - & - & + & 0 \\
\hline 6 & C5 & - & - & +++ & + & - & - & - & - & 0 \\
\hline 7 & C10 & + & +++ & - & ++ & + & - & + & ++ & 0.2 \\
\hline 8 & C10 & - & - & - & + & - & - & + & ++ & 0.3 \\
\hline 9 & $\mathrm{C} 10$ & ++ & ++ & - & ++ & - & + & + & + & 0.3 \\
\hline 10 & C10 & + & + & - & + & + & - & + & ++ & 0.4 \\
\hline 11 & C10 & - & + & ++ & - & - & - & - & + & 0.2 \\
\hline 12 & $\mathrm{C} 10$ & - & + & ++ & - & - & - & - & + & 0.1 \\
\hline 13 & C14 & + & - & +++ & + & - & - & + & ++ & 0 \\
\hline 14 & C14 & - & - & - & + & +++ & - & + & ++ & 0.1 \\
\hline 15 & C14 & - & - & +++ & + & - & - & + & + & 0 \\
\hline 16 & C14 & - & - & - & ++ & ++ & - & + & +++ & 0.3 \\
\hline 17 & C14 & +++ & + & - & - & - & - & + & + & 0.3 \\
\hline 18 & C14 & + & + & ++ & - & - & - & - & + & 0.2 \\
\hline 19 & D5 & + & - & - & + & ++ & ++ & + & + & 0.5 \\
\hline 20 & D5 & + & - & - & ++ & ++ & - & + & + & 0.5 \\
\hline 21 & D5 & - & - & - & + & + & - & - & + & 0.5 \\
\hline 22 & D5 & - & - & - & - & - & - & + & + & 0.4 \\
\hline 23 & D5 & + & + & - & + & + & + & - & - & 0.4 \\
\hline 24 & D5 & + & + & - & + & + & + & - & - & 0.4 \\
\hline 25 & D10 & - & - & - & ++ & ++ & - & +++ & ++ & 0.5 \\
\hline 26 & D10 & - & - & - & - & + & - & ++ & ++ & 0.4 \\
\hline 27 & D10 & - & - & - & - & + & + & + & + & 0.4 \\
\hline 28 & D10 & - & - & - & - & ++ & - & + & + & 0.4 \\
\hline 29 & D10 & + & - & - & - & + & + & - & - & 0.4 \\
\hline 30 & D10 & + & - & - & - & + & + & - & - & 0.3 \\
\hline 31 & D14 & - & - & + & + & - & - & + & ++ & 0.5 \\
\hline 32 & D14 & - & - & - & + & + & - & + & + & 0.4 \\
\hline 33 & D14 & - & - & - & + & +++ & - & + & + & 0.4 \\
\hline 34 & D14 & - & - & - & + & ++ & + & +++ & - & 0.5 \\
\hline 35 & D14 & - & - & - & + & - & - & ++ & ++ & 0.4 \\
\hline 36 & D14 & + & - & - & + & - & - & - & - & 0.5 \\
\hline
\end{tabular}

finger replantation, it was considered to be appropriate to use the rat femoral artery. In order to obtain homogeneous luminal vessel diameter data, only male rats with similar weights were included.

In addition to surgical and technical factors, the success of microsurgery is closely related to patients' health status, health problems, and medications. Several studies have examined the effects of various substances, including low-molecular-weight heparin, steroids, sildenafil, and vinblastine, on enhancing microvascular anastomosis patency [1-6]. However, the benefits of these substances have not been proven. Epigallocatechin gallate was used in our study, as it possesses cardioprotective, anti-atherosclerotic, anti-oxidant, vasorelaxant, anti-aggregant, and anti- inflammatory properties [7-12].

In previous studies, epigallocatechin gallate has been shown to ameliorate brain damage after cerebral artery occlusion [14] and to improve the viability of rat perforator abdominal flaps [16]. Furthermore, epigallocatechin gallate has been suggested to reduce ischemia-reperfusion injuries in rat epigastric island flap [17] and to improve the survival of random-pattern skin flaps [18].

Histopathological assessments of the microanastomosis site were made on days 5, 10, and 14. Day 5 was chosen as a time point because most replanted limbs or free flaps are lost within the first 5 days. Such losses have been attributed to inflammatory cell migration damaging the endothelium and promoting 


\section{Fig. 2. Intimal thickening}

(A) No intimal thickening in a histologically normal vessel in the epigallocatechin gallate group on day $10(H \& E, \times 10)$. (B) Severe arterial luminal narrowing caused by intimal thickening in the control group on day 10 (yellow arrow). More than five cells are seen in the intima $\left(H \& E_{1} \times 10\right)$. Intimal hyperplasia is a cause of arterial occlusion and failure of anastomosis. Epigallocatechin gallate prevents intimal hyperplasia and accelerates pseudointima and intima formation, stimulating endothelial nitric oxide production.
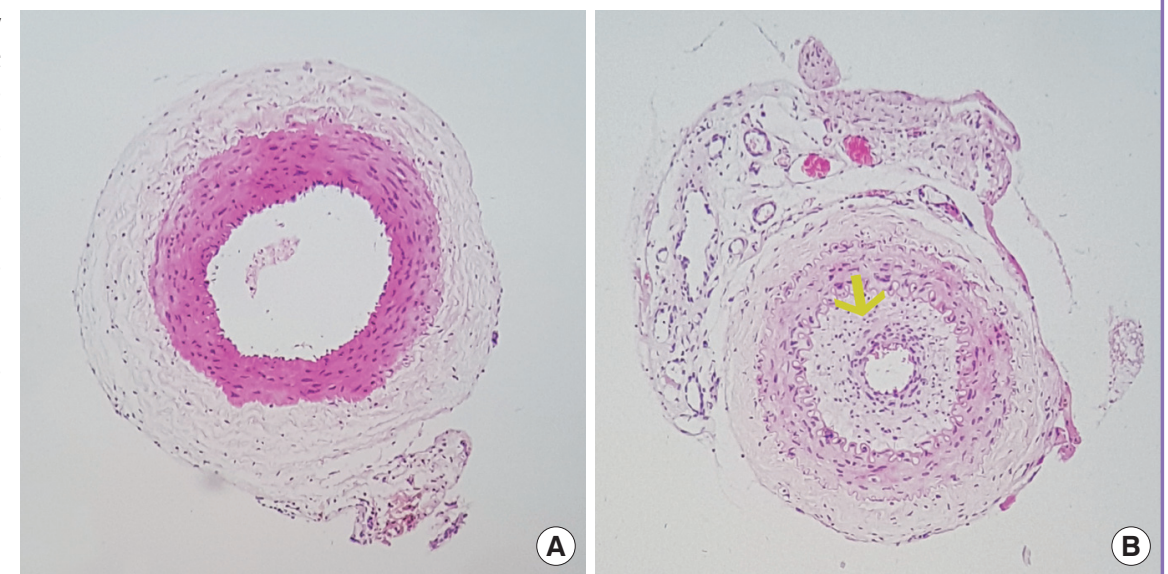

Table 3. Descriptive statistics and comparison of histopathological results between groups

\begin{tabular}{|c|c|c|c|c|}
\hline \multicolumn{2}{|l|}{ Histopathological results } & Control group, median (min to max) & \multirow{2}{*}{$\frac{\text { Drug group, median (min to max) }}{+(- \text { to }+)}$} & \multirow{2}{*}{$\frac{\text { P-value }^{\text {a) }}}{0.065}$} \\
\hline Diameter increase & Day 5 & $-(-$ to -$)$ & & \\
\hline & Day 10 & $+(-$ to ++$)$ & $-(-$ to +$)$ & 0.589 \\
\hline & Day 14 & $+(-$ to +++$)$ & $-(-$ to +$)$ & 0.310 \\
\hline \multirow[t]{3}{*}{ Color change } & Day 5 & $-(-$ to +$)$ & $-(-$ to +$)$ & 0.699 \\
\hline & Day 10 & $+(-$ to +++$)$ & $-(-$ to -$)$ & $0.015^{b)}$ \\
\hline & Day 14 & $-(-$ to +$)$ & $-(-$ to -$)$ & 0.394 \\
\hline \multirow[t]{3}{*}{ Presence of trombus } & Day 5 & $+++(-$ to +++$)$ & $-(-$ to -$)$ & $0.015^{b)}$ \\
\hline & Day 10 & $-(-$ to ++$)$ & $-(-$ to -$)$ & 0.394 \\
\hline & Day 14 & $+(-$ to +++$)$ & $-(-$ to +$)$ & 0.240 \\
\hline \multirow[t]{3}{*}{ Deficiency of elastic lamina } & Day 5 & $+(-$ to +$)$ & $+(-$ to ++$)$ & 0.240 \\
\hline & Day 10 & $+(-$ to ++$)$ & $-(-$ to ++$)$ & 0.240 \\
\hline & Day 14 & $+(-$ to ++$)$ & $+(+$ to +$)$ & 0.699 \\
\hline \multirow[t]{3}{*}{ Intimal thickening } & Day 5 & $-(-$ to +$)$ & $+(-$ to ++$)$ & $0.041^{b)}$ \\
\hline & Day 10 & $-(-$ to +$)$ & $+(+$ to ++$)$ & $0.026^{\text {b) }}$ \\
\hline & Day 14 & $-(-$ to +++$)$ & $+(-$ to +++$)$ & 0.818 \\
\hline \multirow[t]{3}{*}{ Medial thickening } & Day 5 & $-(-$ to -$)$ & $+(-$ to ++$)$ & 0.180 \\
\hline & Day 10 & $-(-$ to +$)$ & $+(-$ to +$)$ & 0.394 \\
\hline & Day 14 & $-(-$ to -$)$ & $-(-$ to +$)$ & 0.699 \\
\hline \multirow[t]{3}{*}{ Advantitial inflation } & Day 5 & $+(-$ to +$)$ & $+(-$ to +$)$ & 1.000 \\
\hline & Day 10 & $+(-$ to +$)$ & $+(-$ to +++$)$ & 0.589 \\
\hline & Day 14 & $+(-$ to +$)$ & $+(-$ to +++$)$ & 0.485 \\
\hline \multirow[t]{3}{*}{ Foreign body reaction } & Day 5 & $+(-$ to ++$)$ & $+(-$ to +$)$ & 0.485 \\
\hline & Day 10 & $++(+$ to ++$)$ & $+(-$ to ++$)$ & 0.394 \\
\hline & Day 14 & $++(+$ to +++$)$ & $+(-$ to ++$)$ & 0.310 \\
\hline \multirow[t]{3}{*}{ Mean luminal diameter (mm) } & Day 5 & 0 (0 to 0.3 ) & 0.45 (0.40 to 0.50$)$ & $0.002^{b)}$ \\
\hline & Day 10 & $0.25(0.10$ to 0.40$)$ & $0.40(0.30$ to 0.50$)$ & $0.026^{b)}$ \\
\hline & Day 14 & $0.15(0$ to 0.30$)$ & 0.45 (0.40 to 0.50$)$ & $0.002^{b)}$ \\
\hline
\end{tabular}

thrombosis formation, particularly within 3-5 days following anastomosis. Pseudointima formation also takes place within 5 days. Since permanent endothelium forms on approximately day 14 in rats and the anti-aggregant effects of epigallocatechin gallate peak on day 10 , additional histopathological evaluations were performed on day 10 and day 14 .
The first striking result of the present study was the significant increase in the mean vessel luminal diameter on day 5 in the epigallocatechin gallate group. This early effect might have stemmed from an early vasorelaxant effect of epigallocatechin gallate on the vessel wall. Early vasorelaxation was also associated with significantly fewer thrombi in the epigallocatechin gallate group. 


\section{Fig. 3. Inflammation and foreign body reaction}

(A) Reduced inflammation and foreign body reactions around the anastomotic site and increased mean vascular luminal diameter in in the epigallocatechin gallate group (yellow arrow, $H \& E, \times 10$ ). (B) Severe foreign body reactions around the anastomotic site in the control group. Diffuse lymphocytes and multiple giant cells are seen around the microvascular anastomotic site. A blood clot is seen at the center of the lumen. Giant inflammatory cells around the anastomotic site, indicating a severe foreign body reaction (red arrows). Sutures (blue arrow) $(H \& E, \times 10)$.

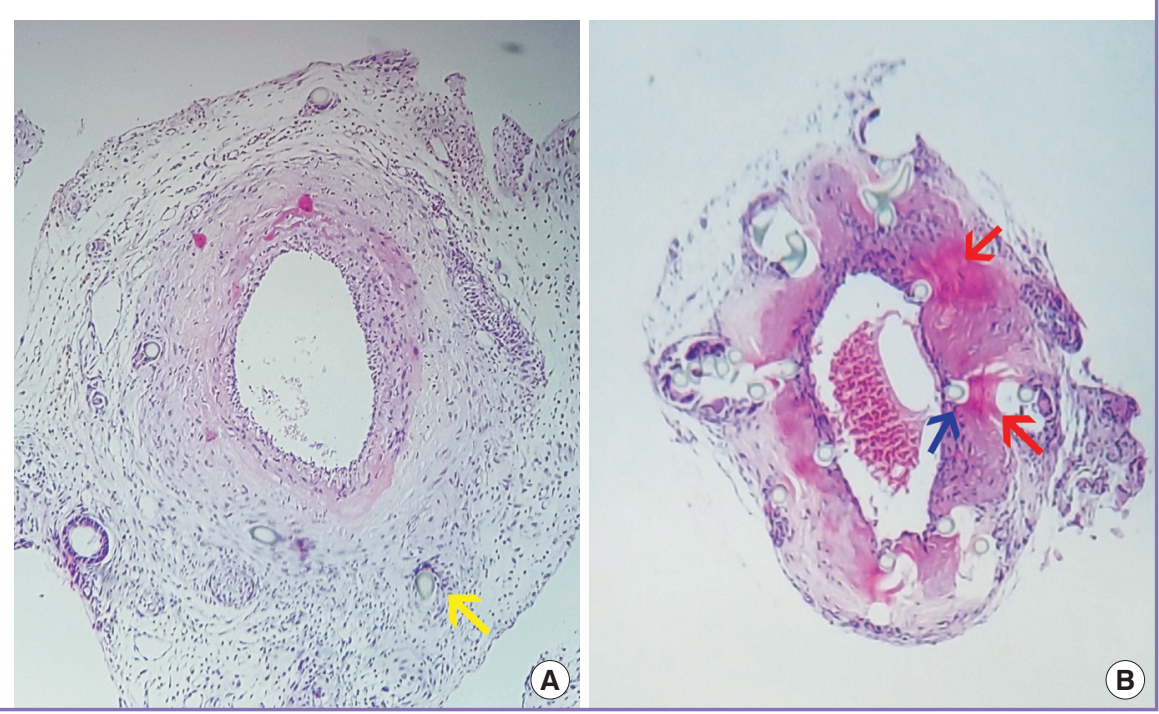

Another important finding of this study was the macroscopic color change in the target vessel. The differences in macroscopic color changes between groups were statistically significant on day 10 and trended towards significance throughout the overall study period. This suggests that epigallocatechin gallate leads to less acute bleeding after anastomosis. The trend towards a significant difference in adventitial inflammation between groups is also consistent with the difference in color change. We also found significant differences in thrombus formation on day 5 and in the overall study period. This prompted us to consider the possibility that epigallocatechin gallate facilitated temporary and permanent endothelial formation and reduced early thrombus formation, which may have been mediated by its acute vasorelaxant effect. These findings also suggest that epigallocatechin gallate might be used to prevent thrombus formation, particularly in the early postoperative period, and increase the likelihood of successful microsurgical repair.

However, the small sample size of the study may have reduced the statistical power and prevented some variables from reaching statistical significance. The intimal thickening in the overall study period was significantly different between groups on days 5 and 10 and was supported by a trend towards statistical significance on day 10. Although epigallocatechin gallate was associated with milder foreign body reactions due to its anti-inflammatory effects, the vasorelaxant effect mediated via calcium channels probably contributed to the significantly greater mean vascular luminal diameter in the epigallocatechin gallate group. The mean luminal diameter was larger on days 5, 10, and 14 in the epigallocatechin gallate group, and it was also different between the epigallocatechin gallate and control groups on days 5, 10, and 14 , consistent with the vasodilatory effects of epigallocate- chin gallate.

Taken together, the histopathological and macroscopic assessments of tissue sections from the microanastomosis site indicate that epigallocatechin gallate improved microsurgical outcomes by providing a smaller thrombus burden, accelerated temporary endothelial formation, marked permanent endothelial formation, reduced inflammation and foreign body reactions around the anastomotic site, and increased mean vascular luminal diameter (Fig. 3). These findings were also supported by hematoxylin and eosin staining.

The available data indicate that epigallocatechin gallate has positive effects on the microcirculation through multiple pathways involving anti-oxidant, vasorelaxant, and anti-aggregant effects. Herein, we have shown that in an experimental model of microvascular arterial anastomosis, administration of epigallocatechin gallate significantly reduced thrombus formation after microvascular repair, particularly in the acute period after surgery. More robust results might be achieved in future large-scale studies, especially if additional methods are incorporated.

Moreover, similar studies on venous anastomoses and random or axial pedunculated skin flaps would also contribute valuable findings relevant to this topic.

\section{NOTES}

\section{Conflict of interest}

No potential conflict of interest relevant to this article was reported.

\section{Ethical approval}

This study was approved by the Ankara University Medical Fac- 
ulty Laboratory Animals Ethics Committee (approval No. 53184147-50.04.04/3835).

\section{Author contribution}

Study concept and design: İğde M. Data acquisition: Öztürk MO. Data analysis and interpretation: Yaşar B. Drafting of the manuscript: Bulam MH. Critical revision of the manuscript for important intellectual content: Ünlü RE. Statistical analysis: Yaşar B. Administrative, technical, or material support: Ergani HM. Study supervision: İğde M. Approval of final manuscript: all authors.

\section{ORCID}

Murat İğde https://orcid.org/0000-0001-8096-2952

Mehmet Onur Öztürk https://orcid.org/0000-0002-4248-7190

Burak Yaşar https://orcid.org/0000-0002-1110-1048

Mehmet Hakan Bulam https://orcid.org/0000-0001-8056-3660

Hasan Murat Ergani https://orcid.org/0000-0002-0305-7032

Ramazan Erkin Ünlü https://orcid.org/0000-0002-3173-0837

\section{REFERENCES}

1. Tatlidede S, Karsidag SH, Tosun U, et al. Effects of vinblastine on healing in microvascular anastomosis. Microsurgery 2003;23:354-8.

2. Karsidag S, Tatlidede S, Tosun U, et al. Effects of vinblastine on microvascular anastomosis healing in diabetic rats. Acta Orthop Traumatol Turc 2011;45:446-52.

3. Eom JS, Koh KS, Al-Hilal TA, et al. Antithrombotic efficacy of an oral low molecular weight heparin conjugated with deoxycholic asset on microsurgical anastomosis in rats. Thromb Res 2010;126:e220-4.

4. Brown JS, Lee N, Lowe D, et al. Effect of short-term high dose of steroids on the healing of microvascular anastomoses in a rabbit model: pilot study. Br J Oral Maxillofac Surg 2000;38: 167-72.

5. Park BY, Kim HK, Kim WS, et al. The effect of botulinum toxin B pretreatment to the blood flow in the microvascular anastomosis. Ann Plast Surg 2014;72:214-9.

6. Pingarron-Martin L, Arias-Gallo LJ. Sildenafil effect on prevention of thrombosis after microsurgical anastomosis: ex- perimental rat model of thrombotic suture. Oral Maxillofac Surg 2014;18:53-8.

7. Wolfram S. Effects of green tea and EGCG on cardiovascular and metabolic health. J Am Coll Nutr 2007;26:373S-388S.

8. Lotito SB, Zhang WJ, Yang CS, et al. Metabolic conversion of dietary flavonoids alters their anti-inflammatory and antioxidant properties. Free Radic Biol Med 2011;51:454-63.

9. Dayoub O, Andriantsitohaina R, Clere N. Pleiotropic beneficial effects of epigallocatechin gallate, quercetin and delphinidin on cardiovascular diseases associated with endothelial dysfunction. Cardiovasc Hematol Agents Med Chem 2013; 11:249-64.

10. Moore RJ, Jackson KG, Minihane AM. Green tea (Camellia sinensis) catechins and vascular function. Br J Nutr 2009; 102:1790-802.

11. Buxton ND, Kaiser RA, Buxton IL. Vascular actions of the polyphenolic catechin gallate EGCG: endothelium-dependent contraction and relaxation. Proc West Pharmacol Soc 2003;46:37-8.

12. Cao Y, Wang D, Wang $X$, et al. (-)-Epigallocatechin gallate inhibits TNF- $\alpha$-induced PAI- 1 production in vascular endothelial cells. J Cardiovasc Pharmacol 2013;62:452-6.

13. Meng M, Li YQ, Yan MX, et al. Effects of epigallocatechin gallate on diethyldithiocarbamate-induced pancreatic fibrosis in rats. Biol Pharm Bull 2007;30:1091-6.

14. Choi YB, Kim YI, Lee KS, et al. Protective effect of epigallocatechin gallate on brain damage after transient middle cerebral artery occlusion in rats. Brain Res 2004;1019:47-54.

15. Unno T, Takeo T. Absorption of (-)-epigallocatechin gallate into the circulation system of rats. Biosci Biotechnol Biochem 1995;59:1558-9.

16. Aksakal IA, Kucuker I, Onger ME, et al. The effect of epigallocatechin gallate on flap viability of rat perforator abdominal flaps. J Reconstr Microsurg 2016;32:256-61.

17. Aslan C, Melikoglu C, Ocal I, et al. Effect of epigallocatechin gallate on ischemia-reperfusion injury: an experimental study in a rat epigastric island flap. Int J Clin Exp Med 2014;7:5766.

18. Cheon YW, Tark KC, Kim YW. Better survival of random pattern skin flaps through the use of epigallocatechin gallate. Dermatol Surg 2012;38:1835-42. 